\title{
Association of Regulatory Factor X 6 gene (rs339331) polymorphism with Prostate Cancer: A case-control study from South India.
}

\author{
Swarnalatha Daram ${ }^{1,2}$, Subhadra Poornima ${ }^{2}$, Syeda Zubeda ${ }^{1}$, Akhilesh $\mathbf{P}^{1}$, Ayyala $\mathbf{V}^{3}$, Srinadh $\mathbf{B}^{4}$, Shailaja \\ $P^{5}$, Sandhya $A^{6}$, Ramakrishna $D^{7}, Q$ Hasan ${ }^{1 *}$ \\ ${ }^{1 *}$ Dept. of Genetics and Molecular Medicine, Kamineni Hospitals, Hyderabad, India \\ ${ }^{1}$ Dept. of Genetics and Molecular Medicine, Kamineni Hospitals, Hyderabad, India \\ ${ }^{2}$ Dept. of Genetics and Molecular Medicine, Kamineni Life Sciences, Hyderabad, India \\ ${ }^{3}$ Dept. of Biochemistry, Kamineni Hospitals, Hyderabad, India \\ ${ }^{4}$ Dept. of Radiology, Kamineni Hospitals, Hyderabad, India \\ ${ }^{5}$ Dept. of Histopathology, Kamineni Hospitals, Hyderabad, India \\ ${ }^{6}$ Dept. of Genetics, Osmania University, Hyderabad, India \\ ${ }^{7}$ Dept. of Biochemistry, Kamineni Academy of Medical Sciences and Research Centre, Hyderabad, India \\ *Corresponding Author: qhasan2013@gmail.com
}

Available online at: www.isroset.org

Received: 30/May/2019, Accepted: 19/Jun/2019, Online: 30/Jun/2019

\begin{abstract}
Prostate Cancer (PCA) is a heterogeneous disease which exhibits clinical variability, morphological differences and molecular marker diversity. Currently, Prostate specific antigen (PSA) evaluation is the only clinically relevant non-invasive marker for PCA screening. A number of genome wide association studies (GWAS) have identified many susceptibility markers for PCA, one of which is a single nucleotide polymorphism (SNP) rs339331, in Regulatory Factor X 6 (RFX6) gene. The present study evaluated this polymorphism g.16677T $>\mathrm{C}$ of RFX6 gene, in PCA, benign prostate hyperplasia (BPH) and controls by PCR using specifically designed primers, followed by restriction digestion. Results show that the frequency of ' $\mathbf{C}$ ' allele is $\mathbf{0 . 7 4}$ in PCA and $\mathbf{0 . 2 0}$ in BPH, which is lower than the frequency in controls, which is $\mathbf{0 . 3 5}$. The ' $\mathbf{C}$ ' allele of RFX6 genotype is significantly associated with PCA $(\mathbf{P}<\mathbf{0 . 0 5})$. This is the first case-control study from India which shows an association of ' $\mathbf{C}$ ' allele of RFX6 gene g.16677T $>$ C polymorphism with high risk of developing PCA and a potential to use it as a biomarker for identifying men at risk of developing PCA.
\end{abstract}

Keywords- Benign prostate hyperplasia, genome wide association studies, gene polymorphism, prostate specific antigen.

\section{INTRODUCTION}

Prostate Cancer (PCA) is the second most frequent and fifth leading cause of cancer death in men [1], [2]. It is estimated that there were 1.3 million new cases of PCA and 3, 59,000 deaths worldwide in 2018. [3]. The American Cancer Society (ACS), USA estimated that 1,74,650 new cases of PCA are being diagnosed and 31,620 men are succumbed to death [4]. According to National Cancer Registry Programme of Govt. of India (NCRP), during the past one and half decade (1991-2015) there is a steep increase in the number of cancer cases in India, which is estimated as 0.8 million cancer cases of which $7 \%(98,000)$ are of PCA, this is an alarming number for India [5], [6].

Age is the major risk factor for PCA, as with age, there is an enlargement of the prostate gland, measured in cubic centimeter (cc) as Prostate Volume (PV), this elevates prostate specific antigen (PSA) in prostate cells and also elevates it in serum. Hence, this has been used as a non-invasive screening marker for early detection of PCA [7], [8], [9].

There are many Genome-wide association studies with complex human diseases and by this method 100 risk loci for PCA have been identified and majority of them are SNPs in the non-coding region of the genome [10], [11]. The SNP, rs339331 in RFX6 gene located on chromosome 6q22 region, reported to be in intron 4 is considered as a common susceptibility locus [12], [13]. This SNP regulates RFX6 gene by recruitment of androgen receptor (AR), forkhead box A1 (FOXA1) and homeobox 
B13 (HOXB13) transcription factor complex thereby, promoting cell migration and proliferation leading to PCA [14], [15], [16].

The aim of the present study was to evaluate the RFX6 (rs339331) gene polymorphism in men with PCA, BPH and controls from South India to identify association, if any with different pathologies of prostate.

\section{RELATED WORK}

Our prior publication shows that men with less than $22 \mathrm{CAG}$ repeats of Androgen Receptor (AR) gene, along with 'GG' genotype of Cytochrome P4503A5*3 (CYP3A5*3) gene polymorphism are at a higher risk of developing PCA. These polymorphisms play an important role in the metabolism of testosterone and are involved in the growth and differentiation of prostate lesions [20].

\section{MATERIALS AND METHODS}

Sample collection:

A total of 312 men were included in the present study, out of which 100 were with PCA, 109 were having BPH confirmed by histopathological studies and 103 were controls without any prostate associated problems and a normal PV established with ultrasound. Ethical approval was obtained from Institutional Ethics Committee of Kamineni Hospitals (Registration Number: ECR/58/Inst/AP/2013) Hyderabad, India.

Method

Isolation of Genomic DNA:

Using salting out method, genomic DNA was isolated from PCA, BPH and healthy controls as described earlier by us [17], [18]. DNA was quantified, checked for the quality using NanoDrop 2000/2000cc (Thermo Scientific ${ }^{\mathrm{TM}}$ ) and stored at $-20^{\circ} \mathrm{C}$ until use [17].

Primers Design and PCR:

SNP rs339331 (T>C) is present in the intron 4 of RFX6 gene, specific primers were designed using NCBI (National Centre for Biotechnology Information) database and primer3plus software (version 2), Forward Primer: 5'CCACAGTGAGACAAACATCACT-3' and Reverse Primer: 3'- ACCCAGTTTCTTCTGGAGC-5' were selected based on melting temperature (Tm) of primers, estimated annealing temperatures, were calculated using Tm calculator application (Thermo Fisher Scientific ${ }^{\mathrm{TM}}$ ) and synthesized at Bioartis Life Sciences Private Limited, Hyderabad, India.

PCR-RFLP:

A three step PCR amplification procedure was carried out using the above-mentioned primers and the PCR products were digested with BspHI (Version 2.0), commercially available restriction enzyme. Upon successful amplification, the digested products were analyzed on ethidium bromide $(\mathrm{EtBr})$ stained 2\% agarose gel electrophoresis [19].

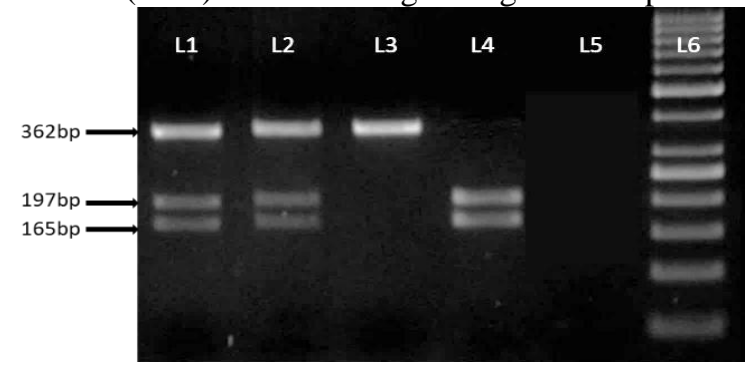

Figure: 1. Etbr added gel image showing genotype of RFX6 gene. Lane 1 \& Lane 2: Heterozygous TC genotype (362, 197/165bp), Lane 3: Homozygous TT genotype (362bp), Lane 4: Homozygous CC genotype (197/165bp), Lane 5: Reagent control and Lane 6: 50bp DNA ladder.

Statistical Analysis:

Association of RFX6 gene with PCA and its related clinical parameters; Allele and genotype frequency in PCA, BPH and

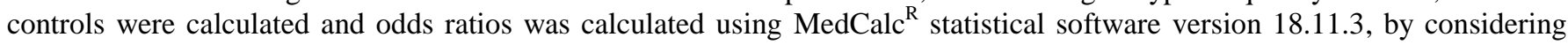
$\mathrm{P}<0.05$ to be significant.

Clinical Characteristics:

III. RESULTS AND DISCUSSION 
The base line clinical characteristics of the cohort studied have been discussed in our previous publication [20].

Distribution of ' $C$ ' allele of RFX6 gene in different groups

RFX6 polymorphism evaluation showed that the ' $\mathrm{C}$ ' allele frequency in PCA is $\mathbf{0 . 7 4}$ which is found to be almost double of that in controls i.e., $\mathbf{0 . 3 5}$, where as in BPH it was even lower, 0.20 . The ' $\mathbf{C}$ ' allele was found to be significantly associated with PCA (OR- 5.1855, 95\%CI- 3.3872 to 7.9383 ) $\mathbf{P}<\mathbf{0 . 0 0 0 1}$.

Distribution of Genotype of RFX6 gene in different groups

Genotyping analysis was done after $2 \%$ agarose gel electrophoresis (Figure: 1.). Of the 100 individuals with PCA genotyped in the present study $1 \%$ were TT, $50 \%$ were TC and $49 \%$ were 'CC' genotype. In BPH and controls TT genotype was $64.2 \%$ and $36.8 \%$, while TC genotype was $33 \%$ and $55.4 \%$, whereas CC genotype was $2.8 \%$ and $7.8 \%$, respectively. The polymorphism follows Hardy Weinberg equilibrium in our population, there was a significant association of 'CC' genotype (OR-11.4093, 95\%CI-5.0190 to $25.9359, \mathbf{P}<\mathbf{0 . 0 0 0 1}$ ) with PCA when compared to controls and it follows a recessive, as well as, a dominant mode of inheritance (CC+TC vs. TT).

\section{Discussion}

PCA is an increasing global health burden in men, the incidence rate of PCA is high in western countries when compared to Asian population. In India due to the lack of comprehensive cancer registries exact number of cancer cases data is not available [5], [6]. Currently men above the age of 50 years are screened for PCA by serum PSA levels in-spite of its several controversies of low specificity leading to unnecessary prostate biopsies in men [7], [21].

RFX6 gene was identified by GWAS as a susceptibility marker for PCA in studies conducted on Japanese and European populations [13], [22], [23], [24], [25] and subsequently confirmed in Chinese population [12]. It belongs to regulatory factor $\mathrm{X}$ transcription factors (TF) family, with winged helix DNA binding domains that binds to cis-regulatory element called HOXbox motif [26]. HOXB13 of HOX-box gene family plays an important role in organogenesis [27]. Earlier studies indicated that, Prostate cancer susceptibility ' $C$ ' allele of RFX6 gene in intron 4 (g.16677T $>$ C) is a risk allele for PCA in other populations [12]. This is the first study from India supporting earlier results.

The frequency of ' $\mathrm{C}$ ' allele according to $1000 \mathrm{G}$ database was $\mathbf{0 . 3 2}$ which is slightly low when compared with our controls which is 0.35. Additionally, rs339331 may be used as a marker to differentiate benign from malignant hyperplasia as the frequency of ' $\mathrm{C}$ ' allele is 0.74 which is more than three times higher when compared to benign which is 0.20 only. ' $\mathrm{C}$ ' allele of RFX6, intron 4 region confers a fivefold increase in PCA risk (Table: 1.). Our results

Table: 1. Allelic frequency and Genotype odds ratios in groups and PCA vs. controls.

\begin{tabular}{|c|c|c|c|c|c|c|}
\hline Group total & \multicolumn{2}{|c|}{ Allelic Frequency } & Risk allele & Allele model & \\
\hline Number & T & C & 'C' $^{\prime}$ & (C vs. T) & Odds ratio, 95\% CI & P Value \\
\hline PCA (100) & $52(0.26)$ & $148(0.74)$ & & PCA vs. controls & $\begin{array}{c}\text { OR-5.1855, 95\% CI- } \\
3.3872 \text { to } 7.9383\end{array}$ & P<0.0001 \\
\hline BPH (109) & $176(0.80)$ & $42(0.20)$ & & Dominant model & & \\
\hline Controls (103) & $133(0.65)$ & $73(0.35)$ & & (CC+TC vs. TT) & Odds ratio, 95\% CI & P Value \\
\hline Group total & \multicolumn{2}{|c|}{ Genotype Frequency } & & PCA vs. controls & OR- 57.8769, 95\% CI- & P=0.0001 \\
\hline
\end{tabular}




\begin{tabular}{|c|c|c|c|c|c|c|}
\hline & \multicolumn{2}{|c|}{} & & & 7.7539 to 432.0076 \\
\hline Number & TT & TC & CC & Recessive model & \\
\hline PCA (100) & $1(1 \%)$ & $50(50 \%)$ & $49(49 \%)$ & (CC vs. TC +TT) & Odds ratio, 95\% CI & P Value \\
\hline BPH (109) & $70(64.2 \%)$ & $36(33 \%)$ & $3(2.8 \%)$ & PCA vs. controls & $\begin{array}{c}\text { OR- } 11.4093,95 \% \text { CI- } \\
5.0190 \text { to } 25.9359\end{array}$ & $\begin{array}{c}\text { P<0.0001 } \\
\text { Controls (103) }\end{array}$ \\
\hline
\end{tabular}

showed an association of ' $\mathrm{C}$ ' allele with PCA similar to other case-control studies from Chinese population [12].

A number of case-control studies of RFX6 gene polymorphism were conducted in Chinese population [26], [27], [28] but this is the first study from India. GWAS on PCA in Japanese men revealed that RFX6 polymorphism is associated with PCA risk but not in European population indicating that there is an ethnic variation [14], [24], [29].

\section{CONCLUSION AND FUTURE SCOPE}

This preliminary study suggests that men with 'C' allele at g.16677 (rs339331) in intron 4 region of RFX6 gene are at a fivefold higher risk of developing PCA this needs to be, further validated in a larger cohort. RFX6 gene rs339331 may be used as a marker to differentiate benign and malignant hyperplasia of prostate as well as for screening and identifying men at higher risk of developing PCA and for recommending them to be on regular surveillance for early diagnosis and management.

\section{ACKNOWLEDGMENT}

We are thankful to Kamineni Hospitals and Kamineni Life Sciences, Hyderabad, India and also to all the volunteers who participated in the study.

There is no conflict of interest.

\section{CONFLICT OF INTEREST}

\section{FUNDING}

This study was supported by Kamineni Hospitals and Kamineni Life Sciences, Hyderabad, India.

\section{REFERENCES}

[1] P. Rawla. "Epidemiology of Prostate Cancer". World Journal of Oncology. Vol. 10(2), pp. 63-89, 2019.

[2] T. Saika, N. Miura, T. Fukumoto, Y. Yanagihara, Y. Miyauchi, T. Kikugawa. "Role of robot-assisted radical prostatectomy in locally advanced prostate cancer". International Journal of Urology, Vol. 25(1), pp.30-35, 2018.

[3] F. Bray, J. Ferlay, I. Soerjomataram, RL. Siegel, LA. Torre, A. Jemal. "Global cancer statistics 2018: GLOBOCAN estimates of incidence and mortality worldwide for 36 cancers in 185 countries". CA: a cancer journal for clinicians, vol: 68(6), pp. 394-424, 2018.

[4] RL Siegel, KD Miller, A. Jemal. “Cancer statistics, 2019”. CA: a cancer journal for clinicians, vol: 69(1), pp. 7-34, 2019.

[5] OP. Singh, V. Yogi, P. Redhu, HU Ghori, A. Pareek, N. Lal. "Role of serum prostate-specific antigen as predictor for bone metastases in newly diagnosed prostate cancer". Journal of cancer research and therapeutics, Vol.1;15(8), pp.39-41, 2019.

[6] A. Mathew, PS. George, KM JK, D. Vasudevan, FV. James. “Transition of cancer in populations in India”. Cancer epidemiology, Vol.1;58, pp.111-120, 2019.

[7] ME. Rezaee, CE. Ward, BD. Odom, M. Pollock. "Prostate cancer screening practices and diagnoses in patients age 50 and older, Southeastern Michigan, pre/post 2012”. Preventive medicine. Vol.1;82, pp.73-76, 2016.

[8] SV. Carlsson, H. Lilja. "Perspective on Prostate Cancer Screening”. Clinical chemistry, Vol. 1;65(1) pp.24-27, 2019.

[9] S Harrison, K. Tilling, EL. Turner, JA Lane, A Simpkin, M. Davis, J. Donovan, FC. Hamdy, DE. Neal, RM Martin. "Investigating the prostate specific antigen, body mass index and age relationship: is an age-BMI-adjusted PSA model clinically useful?". Cancer Causes \& Control, Vol. 1;27(12), pp.1465-1474, 2016.

[10] FM. Schumacher, AA Al Olama, SI. Berndt, S Benlloch, M Ahmed, EJ Saunders, T Dadaev, D Leongamornlert, E Anokian, C Cieza-Borrella, C. Goh. "Association analyses of more than 140,000 men identify 63 new prostate cancer susceptibility loci". Nature genetics. Vol.50(7), pp.928, 2018.

[11] Al Olama AA, Z Kote-Jarai, SI Berndt, DV Conti, F Schumacher, Y Han, S Benlloch, DJ Hazelett, Z Wang, E Saunders, D. Leongamornlert. “ $A$ meta-analysis of 87,040 individuals identifies 23 new susceptibility loci for prostate cancer". Nature genetics, Vol.46(10), pp.1103, 2014.

[12] NN Wang, Xu Y, K Yang, D Wei, YG Zhang, M Liu, XH Shi, SY Liang, L Sun, XQ Zhu, YG Yang. "Susceptibility loci associations with prostate cancer risk in northern Chinese men”. Asian Pacific Journal of Cancer Prevention, Vol.14(5), pp.3075-3078, 2013.

[13] Q Huang, T Whitington, P Gao, JF Lindberg, Y Yang, J Sun, MR Väisänen, R Szulkin, M Annala, J Yan, LA Egevad. "A prostate cancer susceptibility allele at 6q22 increases RFX6 expression by modulating HOXB13 chromatin binding". Nature genetics, Vol.46(2), pp.126, 2014.

[14] IG Mills. "HOXB13, RFX6 and prostate cancer risk”. Nature genetics, Vol.46(2), pp.94, 2014. 
[15] S Jung, H Jin, RV Davuluri. "Identification of candidate regulatory SNPs by integrative analysis for prostate cancer genome data". In Proceedings of the 6th ACM Conference on Bioinformatics, Computational Biology and Health Informatics pp. 278-285, 2015.

[16] Li XH, Xu Y, K Yang, JJ Shi, X Zhang, F Yang, H Yuan, X Zhu, YH Zhang, JY Wang, Z Yang. “Association of THADA, FOXP4, GPRC6A/RFX6 genes and 8q24 risk alleles with prostate cancer in Northern Chinese men”. Journal of BU ON.: official journal of the Balkan Union of Oncology. Vol.20(5), pp.1223-1228, 2015.

[17] S. Poornima, K Subramanyam, IA Khan, Q Hasan. "The insertion and deletion (I28005D) polymorphism of the angiotensin I converting enzyme gene is a risk factor for osteoarthritis in an Asian Indian population". Journal of the Renin-Angiotensin-Aldosterone System, Vol.16(4):1281-1287, 2015.

[18] M Darooei, F Khan, M Rehan, S. Zubeda, E Jeyashanker, S Annapurna, A Shah, S Maddali, Q Hasan. "MED12 somatic mutations encompassing exon 2 associated with benign breast fibroadenomas and not breast carcinoma in Indian women". Journal of cellular biochemistry, Vol.120(1), pp.182-191, 2019.

[19] IA Khan, S Poornima, P Jahan, P Rao, Q Hasan. "Type 2 diabetes mellitus and the association of candidate genes in Asian Indian population from Hyderabad, India". Journal of clinical and diagnostic research, Vol (11), pp. GC01-05, 2015.

[20] S. Daram, Z. Syeda, S. Poornima, S. Boppana, S. Prabhala, A. Sandhya, D. Ramakrishna, Q Hasan. "Association of androgen receptor (AR) $C A G$ repeats and cytochrome P450 $3 a 5 * 3$ (cyp3a $5 * 3)$ gene polymorphisms in men with prostate cancer from south India". Journal of clinical and diagnostic research, 2019. (Accepted on $1^{\text {st }}$ June 2019).

[21] P Korti, S Prabhala, E Jayashankar, AK Deshpande. "Study of transrectal ultrasound guided biopsies of prostate in correlation with serum prostate specific antigen level”. Indian Journal of Pathology and Oncology, vol: 4(4), pp. 604-610, 2017.

[22] S Lindström, FR Schumacher, D Campa, Albanes, G Andriole, SI Berndt, HB Bueno-de- Mesquita, SJ Chanock, WR Diver, JM Ganziano, SM Gapstur. "Replication of five prostate cancer loci identified in an Asian population results from the NCI Breast and Prostate Cancer Cohort Consortium (BPC3)". Cancer Epidemiology and Prevention Biomarkers, vol: 21(1), pp. 212-216, 2012.

[23] M Wang, F Liu, AW Hsing, X Wang, Q Shao, Qi J, Y Ye, Z Wang, H Chen, X Gao, G Wang. "Replication and cumulative effects of GWASidentified genetic variations for prostate cancer in Asians: a case-control study in the ChinaPCa consortium". Carcinogenesis, Vol.23;33(2), pp.356-360, 2011.

[24] R Takata, S Akamatsu, M Kubo, A Takahashi, N Hosono, T Kawaguchi, T Tsunoda, J Inazawa, N Kamatani, O Ogawa, T Fujioka. "Genomewide association study identifies five new susceptibility loci for prostate cancer in the Japanese population”. Nature genetics, Vol.42(9), pp.751, 2010.

[25] R Eeles, C Goh, E Castro, E Bancroft, M Guy, AA Olama Al, D Easton, Z Kote-Jarai. "The genetic epidemiology of prostate cancer and its clinical implications". Nature reviews Urology, Vol.11(1), pp.18, 2014.

[26] S Aftab, L Semenec, JS Chu, N Chen. "Identification and characterization of novel human tissue-specific RFX transcription factors. BMC evolutionary biology", Vol.8(1), pp.226-237, 2008.

[27] S Bhatlekar, JZ Fields, BM Boman. "HOX genes and their role in the development of human cancers. Journal of molecular medicine", Vol.1;92(8), pp.811-823, 2014.

[28] D Sugiaman-Trapman, M Vitezic, EM Jouhilahti, A Mathelier, G Lauter, S Misra, CO Daub, J Kere, P Swoboda. "Characterization of the human RFX transcription factor family by regulatory and target gene analysis”. BMC genomics, Vol.19(1), pp.181-196, 2018.

[29] QZ Long, YF Du, XY Ding, X Li, WB Song, Y Yang, P Zhang, JP Zhou, XG Liu. "Replication and fine mapping for association of the C2orf43, FOXP4, GPRC6A and RFX6 genes with prostate cancer in the Chinese population". PLoS One, Vol.7(5), e37866, pp. 1-6, 2012.

\section{AUTHOR PROFILE}

Mrs. Qurratulain Hasan pursued PHD in Genetics from Osmania University, Hyderabad in 1989. She is currently working as Sr. consultant and HOD in the department of Genetics and Molecular Medicine. She has 32 years of experience in teaching, diagnostics, research and counselling. To her credit 17 students have completed $\mathrm{PhD}$ under her guidance. She has published more than 122 research papers in reputed international journals. Her main research work focuses on cytogenetics, molecular genetics, epigenetics, diabetes, cancer and stem cells. (Corresponding Author) 